
\title{
25 Research Soure \\ Drivers of Substance Use and Related Disorders Among Young People in a Peri-urban District of Ghana
}

\section{Vida Kasore}

Kwame Nkrumah University of Science and Technology

Enoch Acheampong ( $\nabla$ caposterl@yahoo.com)

Kwame Nkrumah University of Science and Technology https://orcid.org/0000-0002-6306-4920

Frances Emily Owusu-Ansah

Kwame Nkrumah University of Science and Technology

Mark Owusu

Catholic University College

Ampeh Unity Worlanyo

Kwame Nkrumah University of Science and Technology

Apaaya Gloria Winifred Nyabamah

Kwame Nkrumah University of Science and Technology

\section{Research}

Keywords: Substance abuse, Effects on the Youth, Rehabilitation intervention, Ghana

Posted Date: October 25th, 2021

DOI: https://doi.org/10.21203/rs.3.rs-989406/v1

License: () (1) This work is licensed under a Creative Commons Attribution 4.0 International License. Read Full License 


\section{Abstract}

Background: Substance use-related disorders have become a major psychiatric issue globally. The energetic youth who contribute meaningfully to national development are the most affected population by this social menace. This study aimed to examine the knowledge and perception of the youth on substance use-related disorders and the perceived effects on their lives.

Methods: The study used a qualitative approach to explore the perceptions of substance use-related disorders in the Kwabre-East Municipality of the Ashanti Region of Ghana. The purposive technique was used to select 35 participants based on a set of inclusion and exclusion criteria. The data were gathered through focus group discussions and interviews in the Twi language and audio-recorded. Data were transcribed from Twi to English in a written form. The data were categorized into themes based on similarities and differences. Thematic analysis was used to analyze the data. The emerged themes have been presented as main findings, which are supported by quotations from the participants.

Results: The study identified that substances commonly abused by the youth were alcohol, tramadol, gasoline product, glue, and marijuana. Again, it was found that peer influence, poor parental control, and loss of a job (poverty), perceived academic enhancement, and imitation of role models were factors that caused substance abuse among the youth. In addition, the following were identified in terms of the effects: mental illness, cardiovascular conditions, family exclusion, insecurity, and stigmatization.

Conclusion: The initiation and implementation of drug preventive interventions by relevant stakeholders are crucial in preventing the commencement of any undesirable behaviour among the youth as far as substance abuse is concerned.

\section{Introduction}

Substance addiction is one of the most common social problems faced by many nations worldwide [1]. Alcohol and illicit drug use have harmful effects on the life of the individual, family, and the nation as a whole in terms of health and livelihood [1]. Aside from socioeconomic effects, individuals with substance addiction are prone to criminal conduct, homicide and suicide, family and marital issues, cardiovascular diseases, and other impairment conditions [2]. There are several reasons for which a person can abuse substances. Biological and hormonal changes can induce adventurous risk-taking behaviors [3]. The desire for independence from parental authority or values in the youth can precipitate substance use [4]. Others have found that living in abject poverty or social isolation, bereavement, and job loss can also increase the desire for alcohol and other drug use $[5,6]$.

According to the 5th edition of the Diagnostic and Statistical Manual of Mental Disorders (DSM-V), [7] substance abuse is a maladaptive pattern of substance use characterized by recurrent and significant threats related to prolonged use of substances. This revised manual introduced a single diagnostic category termed "substance use disorders" which combines the former two categories (substance abuse and substance dependence) in the previous edition (DSM-IV). The criteria for diagnosing substance use 
disorders are primarily based on cravings, relapse, and withdrawal symptoms [7, 8]. There is a plethora of evidence in the literature that emphasizes the deleterious effects of substance abuse. Preventable injuries and disabilities are sustained, and many lives are lost due to alcohol or drug abuse $[9,10]$. An opioid, for example, is responsible for two-thirds of 585,000 people who died due to drug use in 2017 [10]. In addition, millions of persons who become addicted to substance use or contract diseases, as a result, do not all receive needed treatment [11]. Unfortunately, the vulnerable or at-risk group is the youth and young adults between the ages of 18-30, a clear 'waste' of most productive years [12]. The report also suggested that Substance Use Disorders (SUDs) have heavy economic implications, costing billions annually [13, 14].

The situation is not different in Africa. It is estimated that 7.7\% (38 million) of the African population abuse cannabis annually, which is far higher than the $3.8 \%$ of cannabis users among the global population [15]. In 2014, Benin recorded about $45 \%$ of drug abuse cases whiles Cameroon recorded $75-$ $80 \%$ of abuse cases, with the youth being the predominant group in both countries [16]. In 2019, it was also reported that about $14.4 \%$ of Nigerians used drugs in the last couple of years, and this is more than twice the global average of 5.6 [11].

The same situation is mirrored in Ghana, where substance abuse is the third highest cause of psychiatric cases at the Komfo Anokye Teaching Hospital (KATH) and close to $90 \%$ of the psychiatric cases are substance use related [17]. Drug abuse and drug dependence have become the leading cause of mental impairment in the country among the youth and some of them choke the few psychiatric hospitals, rehabilitation centres, prayer camps, or end up on the streets [18]. Many who need appropriate interventions for addiction do not receive it because of limited state-funded care facilities and unaffordable private rehabilitation centres $[11,18]$. This situation impedes national development.

Appropriate context-specific interventions must be evidence-based. Yet, there is a paucity of research on alcohol or drug abuse and related disorders in Ghana due to limited research, lack of opportunities for publication, and poor record-keeping in remote areas [19]. Admittedly there has been considerable research in the last three decades on alcohol or drug abuse in some African countries though in small sample sizes. Resource constraints and documentation challenges regarding the true patterns of substance abuse and related risks or implication have hampered research in the area, making reliance on secondary sources a practice [19]. Yet, secondary sources fail to examine the knowledge and perception of the abusers on drug abuse and the disorders associated. This study sought to bridge this gap. From the perspective of the youth, in-depth information on the subject could help design programs that deter them from engaging in indiscriminate substance abuse.

Over the last two years, a number of the youth in the Kwabre-East Municipality within the Ashanti region have been involved in a riot and criminal behaviours due to abuse of illicit drugs, which even led to the closure of one Senior High School [20]. However, in the reports that followed, it appeared that the investigators failed to examine what led to the abuse of the drugs. Therefore, this study examined the 
perception of the youth on substance abuse-related disorders and the effects on the lives of the youth in the Kwabre East Municipality of the Ashanti Region of Ghana.

\section{Methods}

The study employed a descriptive, qualitative design. In-depth understanding and description of the phenomenon understudy was facilitated by this approach [21].

Purposive and snowball sampling techniques were used to recruit people between the ages of 15 and 35 living in the Kwabre-East Municipality and who could provide detailed information on the questions of interest in the study. In addition, the researchers were assisted by a participant who was a recovering substance abuser and who led them to others he knew who were substance abusers. It was necessary because, given the sensitivity of the subject under study, it was difficult to penetrate the community.

The inclusion criterion was that participants should have abused drugs or know others who have or who are abusing drugs. In addition, they must live in the district and be within the desired age category. The researchers initially contacted the participants at their homes and workplaces. They explained the purpose of the study to them before scheduling a date for the interviews and focus group discussions. Participants gave their informed consent before participating in this study. Based on the 'Principle of Saturation' [22], a total of 35 participants (22 males and 13 females) participated in the study. Nine participants completed one-on-one interviews, whilst the remaining 26 participants were divided into two separate focus groups.

The data were collected in the local language (Twi) through face-to-face interviews and focus group discussions. The interview guide focused on the following areas: knowledge of commonly abused drugs, perceptions on substance abuse, factors that influence substance use, abuse and dependence, social and health effects of substance abuse, and the interventions for substance abuse.

Principal investigators trained research assistants before data collection commenced to ensure consistency of procedure. The data was recorded with an audio recorder. Each interview and the focus group discussions lasted approximately 40 and 90 minutes, respectively. The interview took place in 6 communities within the district. Each interview or Focus Group Discussion was audiotaped and transcribed verbatim, after which the data were coded and analyzed based on themes, using thematic analyses.

Data curation, once collected, included reading through the transcripts, highlighting codes that represented specific terms used by the participants to ascribe meaning to their thoughts, opinions, or actions, and spell checking to avoid misinterpretation of data. Five main themes emerged. Sub-themes were developed and linked together. Some of these sub-themes have been cited as quotations to support the findings.

\section{Results}




\section{Socio-Demographic Characteristics and substance abuse}

The data from table 1 revealed that people who abuse drugs start at an early age, between 14 and 18 years of age. The data further revealed that about $80 \%$ of males abuse substances as against $20 \%$ of females. Most of the drugs are illegal, and it takes people who are brave to use them. Men are considered as risk-takers in Ghanaian societies, while women are considered vulnerable besides, it is very shameful for a woman to use drugs in public [23]. The data revealed that most of the women who abuse drugs hide doing it, and they use the drugs to be able to manage certain disorders. Some participants also shared that a person's religious background can deter them from abusing drugs. In addition, a person's marital and employment status can either deter or influence their drug use.

“... madam, I started using drugs when I was unemployed; I became frustrated, especially whenever my parents insult me and tell me to find a job to do. I started to use drugs to forget my frustrations..." (Male participant individual interview).

"... all the guys in my area who do drugs are single, and they have no meaningful job. I only see a few guys who are married and still do drugs..." (Male participant, focus group discussion).

"... I and my squad take drugs sometimes to prove who is a guy... when you cough it means you are a woman..." (Male participant, individual interview).

"... women feel shy to smoke or drink outside... they usually send their children to buy alcohol for them to gain an appetite for food..." (Male participant, focus group discussion).

\section{Types of substances abused by the youth}

Most participants identified the following as drugs commonly abused by the youth: "wee" (Marijuana), "Akpeteshie" (alcohol), cigarette, cocaine, pethidine, heroin, diazepam, tramadol, super glue, dried faeces, and gasoline products. Almost all the male participants agreed they had used one or more of the above drugs before. In addition, all the participants claimed that they know people who constantly abuse at least one of the above drugs.

"..I have smoked wee before, and I know many people who mix alcohol with wee, tramadol... they drink all the time; some also inhale the gas and dried faeces." (Male participant, individual interview).

"... my father will kill me if I ever use any drug; I know some guys in my area who sniff cocaine, and I have heard that some also inject pethidine whiles others inhale super glue ..." (Male participant, individual interview).

Substance abuse affects the individual's dressing and composure. The majority of the participants perceived substance abusers as "mad" people who have lost self-control and meaning in life. They openly admitted that they would not associate with substance abusers for fear that they may end up being like 
them. However, some of the participants who were substance abusers had a different opinion about themselves.

"... as for me, I cannot befriend someone who is a drug addict...they can easily hurt you besides my parents will not even approve our relationship if we should fall in love" (Female participant, focus group discussion).

“...sis! What are they saying... I have been taking tramadol and marijuana for years now, look at me, am I shabbily dressed?" (Male participant, focus group discussion).

"I know a lot of people who abuse substances, yet they're perfectly okay when you are not told you won't notice it..." (Male participant, focus group discussion).

\section{Causes of Substance Use and Abuse among the youth}

The findings revealed that the use and abuse of drugs among the youth stem from social and economic factors. These factors are categorized under poor parental support, bereavement, peer influence and curiosity, strenuous work, job loss, unemployment issues, academic performance enhancement, overcoming stage fright, and imitating role models and health or medical reasons.

\section{Poor parental support}

The findings revealed that most parents lack basic parenting skills. Therefore there is little or no bond between them and their children, especially when the care of the child becomes one parent's responsibility due to divorce.

"... sister, it's not easy to be separated from your parents... I and my senior brother were brought up by our stepmother, who doesn't care about our movements, and as a result, my brother joined bad friends. My brother cannot live a day without wee, and I know it's because of my parents' separation" (Female participant, individual interview).

"......Most young people join friends to abuse tramadol and other drugs because their parents don't check their movement and besides there is no good relationship between them and their children" (Female participant, focus group discussion).

\section{Bereavement}

The participants shared that the bereavement of a loved one increases the desire for alcohol and other drug use, and dependence becomes a coping mechanism.

"I... know a young guy who lost his family through a motor accident and he could not bear the pain and started drinking alcohol to forget his pain, and now he abuses alcohol, wee, and tramadol" (Female participant, individual interview). 
"I ... lost my mom almost two years ago, and during that time ... I couldn't accept she was gone like that, I thought of taking my life whenever I was alone and I started drinking alcohol to forget my pain." ( Male participant, individual interview).

\section{Peer influence and curiosity to implement}

The findings further revealed that some of the youth join their peers to abuse drugs to fit in whilst others just want to experiment with dazedness. Some people also abuse drugs out of frustration.

"... I started smoking marijuana out of curiosity. I had often heard people say that the weed can make you feel high, and I wanted to experience that..." (Male participant, focus group discussion)

"... I know some guys who are doing drugs because their friends introduced them, and there are others too once you join their squad you will have to smoke wee and drink alcohol by all means" (Female participant, focus group discussion).

\section{Strenuous work}

Some of the participants revealed that some physical activities are very demanding and therefore many people turn to use different types of drugs to carry out the activities. Carving, Construction work, Sexual activity, Galampsey (manual mining), and Weaving are all examples of physical activities in which many people need drugs to boost their stamina. The following cites indicate participants shared opinions:

"... I once took quick action tablet to gain more energy to sit for a long time to weave many pieces of kente but I noticed I was becoming addicted and so I stopped, but some of my colleagues mix it with tramadol and other substances" (Male participant, individual interview).

"...some of us take tramadol and alcoholic drinks to gain stamina and to enhance sexual activities." (Male participant, focus group discussion).

\section{Loss of job and unemployment issues}

The findings also revealed that some youth who have either lost their job or are unemployed get frustrated and join other substance abusers in ghettos to run away from responsibilities and avoid family members who constantly remind them to look for a job.

"...my uncle was laid off permanently and after a while he became frustrated. He could no longer take care of his family. He spends most of the time smoking weed with his friends in ghettos and eventually his wife divorced him..." (Female participant, individual interview).

\section{Enhancement of academic performance}

The majority of the participants revealed that they abused substances to enhance academic performance. They were of the view that substances like stimulants make them feel more alert and 
confident. It also helps them in long hours of studies without feeling tired. However, some of them also shared that drugs can make students go mad and end up performing poorly.

“... I have been smoking marijuana since Junior High School. and I cannot study without a puff... it helps me to study" (Male participant, focus group discussion).

"...in school, I had a friend who could take 3 bottles of energy drinks mixed with marijuana at a time to stay active and study overnight... his Cumulative Weighted Averate dropped at the end and he started saying weird things and had to defer the course for treatment..." (Male participant, focus group discussion).

\section{Overcoming Stage Fright and Imitating Role Models}

The majority of the participants admitted that stage fright and role modelling lead to substance use and abuse. They explained that some celebrities cannot perform on stage without taking drugs. Some of these celebrities whom the youth look up to consistently post pictures of themselves drinking and getting high on various social media platforms. The youth who have some of these celebrities as their role models turn to abuse drugs intending to be like them (their role models). That notwithstanding, some also believe that certain advertisements on social media can lead to substance abuse among the youth. However, other participants did not see anything wrong with alcohol and drugs advertisement because it involves celebrities.

“... most of our upcoming celebrities are shy in nature and cannot take shows without taking drugs... some of the youth copy them blindly..." (Female participant, focus group discussion).

"Sister, as for me I can't stand the sight of beer advert on Television oo, especially when they pour it into the glass / start salivating..." (Male participant, focus group discussion).

"If alcoholic drinks are bad why do celebrities advertise on Television ...it means it's good and I can't stop drinking it." (Male participant, focus group discussion).

\section{Health or Medical Reasons}

Some participants also revealed that some people with disorders such as anxiety, depression, and sickle cell use drugs intending to alleviate psychiatric symptoms and pain; however, they end up abusing the drug due to its constant use. They further indicated that when one takes a particular drug for some time, the body becomes immune to it, and the individual increases the dosage to have the same effect.

"...some of my colleagues with sickle cell have been spending all their salaries injecting pethidine and at times they steal that of other patients' because they have become addicted." (Female participant, focus group discussion).

\section{Effects of Substance Abuse}


The data revealed that substance abuse has several effects ranging from health, social, and economic with dire implications on the individual, their family, and society as a whole.

\section{Individual-level health effects of substance abuse}

The majority of the participants revealed that constant use of drugs could lead to loss of appetite for food, trembling, addiction, mental illness, and lung and liver diseases. Again, some participants added that alcohol abuse could lead to making bad decisions such as drunk driving, resulting in serious motor vehicle accidents. Some of the drugs also make people lose self-control and engage in unprotected sex, which could lead to the spread of sexually transmitted diseases.

"I work in a hospital, and I know that most of the psychiatric cases we record are due to drug injection because it goes straight into the bloodstream and it can collapse the vein..." (Female participant, focus group discussion).

".... My brother abuses alcohol, and most of the time he doesn't eat; he is always shaking..." (Female participant, individual interview).

\section{Health effects of substance abuse on the family and the society}

Some participants added that the abuse of drugs could equally affect the abusers' families and society at large. For example, some families suffer from depression because of the stigma associated with addiction. Society also feels insecure because most substance abusers are perpetrators of violence. In addition, they engage in theft and robbery to be able to afford their drugs. Below are some of the quotes describing some of the participants' opinions on the health implications of substance abuse:

"My elderly sister died of lung cancer because she abused alcohol and cigarette for a long time. My mother, who was a trader, spent her entire fortune treating her... my mother became depressed when she lost everything and finally died of stroke" (Female participant, individual interview).

"It is not easy to have a substance abuser in your family. We are from a wealthy family and my cousin abuses tramadol and marijuana... he is always at the station trying to load passengers for coins. Sometimes I wish he is not living..." (Female participant, individual interview).

“... some wee smokers in our vicinity have been stealing people's property...your heart is always on fire when you step out; for fear that they will come and break your door open..." (Female participant, individual interview).

"... it is very cheap to sleep with women in the ghetto... I and my friends sometimes do sex gala (competition)..." (Male participant, focus group discussion).

\section{Socioeconomic Effect of Substance Abuse}


The abusers experience family exclusion or rejection. Most substance abusers are not invited during family gatherings or deliberations, and even when they happen to be around, their opinions are not considered because they are seen as 'mad'.

"my family does not invite me when they're discussing family issues... even when I am around, my views are not considered because they think that I'm under the influence of alcohol..." (Male participant, individual interview).

The data further revealed that drug abuse could lead to depletion of the users' income which, in effect, result in a lack of care for families and other responsibilities. Other participants also added that substance abuse leads to loss of jobs and unemployment due to the stigma associated with addiction.

"... my father spends all his money on alcohol...I have 3 siblings, and none of us was able to complete S.H.S." (Female participant, individual interview).

"I used to work as a sales personnel in a certain company, but now I am jobless because I have been taking alcohol and my boss fired me..."(Male participant, individual interview).

The data also revealed that the abuse of substances among the youth could lead to low productivity in the country; because the abusers' performance at work is usually compromised by hangovers, health complications, and lack of focus. Moreover, the cost of treating SUDs is very high, and drug abuse also increases pressure on state owed rehabilitation facilities. Therefore, families are compelled to send them to private rehabilitation centres, which are usually very expensive. Aside from spending huge sums of money on SUDs treatment, the family also spends huge sums of money on settling crime issues.

"... the youth are the future leaders of its nation, and therefore losing them to addiction implies that the nation has no future..." (Male participant).

\section{Intervention for Substance Abuse}

Some of the participants indicated that the ultimate intervention for drug addiction is in-patient rehabilitation. They also indicated that drug abuse and addiction are well managed with psychosocial therapies in rehab centres; however, they are inadequate in the district. Other participants also added that even though rehabilitation is the best intervention for substance abuse, people in the rehab centres are usually labelled as "abnormal," which impedes rehabilitation progress and deters other people from seeking help.

"I did my NSS in a rehab centre, and I learned that psychiatric cases are different from substance abuse... counselling is used to manage drug issues... unlike psychiatric issues which are managed with medicine..." (Male participant)

"... I have been taking tramadol and wee, but I know it's not good for me. I want to stop, but I can't go for rehabilitation because people will start looking at me in some way..." (Male participant). 
"...both substance abusers and people with mental illness are the same... they have all lost their mind and need to seek asylum...the treatment centres are very few that is why a lot of mad people are on the streets" (Male participant).

\section{Discussion}

The condition in which people find themselves could have some influence on their drug use, understanding, and perception about substance abuse and their related disorders. This finding confirmed that the possibility of a man becoming a substance user is three times that of a woman [25]. In addition, gender roles can influence substance use and abuse. Culturally, adventurous roles are reserved for men, and, therefore, they initiate and take in more drugs to prove how strong and brave they are. On the other hand, women are considered in society as faint-hearted and vulnerable. Consequently, shame and stigma are attached to their use or abuse of alcohol and drugs, and therefore it was not surprising that substance use and abuse are prevalent among men than women. However, the fact that the findings further confirmed the National Institute of Drug Abuse [25] that most women hide using drugs to cope with pain, sleeping, and eating disorders means that substance use is also gradually becoming a growing problem among females. If care is not taken, the effect can be very dangerous as it could lead to fetal alcohol syndrome, birth defects and developmental disabilities in pregnant women.

Most substance users initiate the use between 14-18 years of age $[12,26]$. The participants were very much aware of the different types of drugs that are abused daily. The study revealed that aside from alcohol, cigarette, and marijuana, most of the youth also abuse opioid medication such as tramadol, diazepam, and pethidine and volatile substances, including glue and gasoline products. This confirms that marijuana is the major drug commonly abused among the youth in Ghana [28]. However, it was also evident that tramadol and other volatile substance use have also gained popularity among the youth. Substance abuse is inherently linked to mental illness and the introduction of new drugs into society will increase mental illness and consequently bring pressure on public psychiatric hospitals [18]. It was not surprising that Equal [17] reported that about $90 \%$ of the psychiatric cases recorded at Komfo Anokye Teaching Hospital were substance use-related disorders. Since the government subsidizes psychiatric treatment, the increase in psychiatric cases will increase government expenditure. Resources that could have been invested in developmental projects to benefit the entire populace are spent on a minute population. This is a wake-up call for the Ministry of Health, Ghana Health Services, Narcotic and Drug Control Board, and other stakeholders who are interested in addressing substance abuse to come together and fight this social canker.

There are several reasons for which people abuse drugs. The findings affirm Alberta Alcohol and Drug Abuse Commission, $[25,28,29]$ that people with chronic health conditions such as depression and other psychiatric conditions use prescribed opioid pain relievers to alleviate their pain and the psychiatric symptoms which end up worsening their condition in the long run and consequently increase their risk of developing an addiction. The prolonged use of the drugs can also trigger certain mental conditions and make the individual develop dual diagnoses since substance abuse co-exists with mental conditions. The 
study further revealed that peer pressure and poor parental care are the most predominant factors for substance use and abuse among the youth. The study revealed that most of the youth who abuse drugs are lured into it by their friends though few of the youth on their own, experiment with the use of drugs "to feel high" because of the temporal euphoria associated with the use of these drugs [25]. This calls for appropriate parental supervision and control in the areas of discipline and constant monitoring of behaviours.

The findings confirm Clark, Thatcher \& Maisto, [30] that poor parental supervision leads to adolescents' substance use and abuse. Similarly, the findings showed that parental supervision becomes a problem when the care of the child becomes the sole responsibility of one parent due to divorce. Therefore, the ministry of gender, children, and social protection, and other human rights activists must also come together to ensure that the care of children becomes a corrective responsibility.

Another major factor leading to substance abuse among the youth is overcoming stage fright and imitating role models. The findings showed that what the youth see on social media makes them susceptible to drug use and abuse [31]. Consistently, Hilliard finds that some celebrities consistently post pictures of themselves drinking and getting high on various social media platforms giving their followers, who are mostly the youth, the wrong impression that it is appropriate to do the same [31, 32]. Although Food and Drugs Authority (FDA) has banned celebrities from endorsing alcoholic drinks, some famous media presenters continue to endorse alcoholic drinks on their shows, and most youth look up to some of these personalities. It is a pity that the Food and Drugs Authority and Advertisement Regulatory bodies in the country are silent. There is no doubt whatsoever that the alcoholic industry can be a source of revenue for the government and help reduce the country's unemployment rate. Nevertheless, that is not worth the resources government spends in treating alcohol and drug-related diseases.

Moreover, the study results showed that the youth use substances to increase stamina and relieve stress. Some of these stressors which predispose the youth to drug use include loss of a loved one, unemployment, and loss of a job which usually results in poverty. These results from the study support what Amoakwa-Fordjour, and Appiah identified that living in poverty or social isolation, bereavement, being unemployed or highly stressed in work increase the desire for alcohol and other drug use especially among the youth and subsequently addiction becomes a coping mechanism $[5,6]$. The use of drugs will not completely take away the above stressors, and the repeated use of the drugs will only result in addiction and other chronic mental conditions. Besides, the resources that the family members and the government will have to spend in treating the individual are not worth the money that was used to buy the drugs. Family members, friends, and society have to support the youth to manage stress positively. Lastly, it was evident in the findings that the youth abuse substances to enhance academic performance. There is a clear line between long hours of study and concentration. Some drugs can stimulate a person to spend long hours studying without feeling tired, but that cannot be taken for concentration in studies. The repeated use of drugs can affect how the brain functions [32]. This is more likely to lead to substance use-related disorders, which can also lead to theft, poor academic performance, and dropping out, as was evident in the findings. 
The findings revealed that substance abuse is associated with a wide range of long-term and short-term health effects on the individual abuser. The effects of substance abuse do not only rest in the individual abuser but also the family and society suffer from it. The substance being chemicals can affect the individual's body and brain function depending on the type of drug, the quantity, and frequency of use. The effect of substances on the body includes mental illness, addiction, and sexually transmitted diseases since most substance abusers engage in unprotected sex and share the needle. This means that family members, friends, and people in society are at a higher risk of contracting infectious diseases. In effect, the rate of HIV/AIDS will escalate in the country, and the government will have to spend huge sums of money on managing it. Everyone in the country will be affected in one way or the other. Therefore the Government, Ministry of Health, Public Health Officials, and other stakeholders must come together to fight this drug issue. The socioeconomic effects of substance abuse on the individual abuser, their family, and society cannot be overemphasized. The findings revealed that most substance abusers usually lose their job due to poor performance, and they rely on their families, and the public for support whilst others end up on the streets and engage in theft and robbery to afford the drugs and also to survive. Some also experience societal exclusion, rejection by family members and friends. Substance abuse or addiction leads to a breakdown of family relationships and brings shame and disgrace to the family members due to the stigma associated with addiction. The findings also showed that addiction increases the crime rate in society. This means that the very existence and survival of society are threatened. This calls for serious collective efforts of all stakeholders who are working together to reduce the menace of drug use among the youth.

Many researchers have consistently shown that substance abuse is a public health concern $[19,23]$. However, they failed to look at proper ways to manage the condition, and this study fills that gap. Every human being has struggles and needs help in one way or the other. The findings revealed that the best way to deal with SUDs is to go for rehabilitation which includes psychosocial therapy and pharmacotherapy, which are usually undertaken in a residential facility. However, limited rehabilitation services in the country and the stigma associated with addiction make it very challenging. Therefore, it is not surprising that 1 in 7 individuals receive treatment for SUDs each year [11]. Unlike the recent pandemic (coronavirus), cancer, and other health conditions, it is pathetic that little attention is given to substance abuse and addiction, which can claim many lives. It is, therefore, necessary for the government, the Ministry of Health, and Public Health Officials to come together to sensitize the general public on the seriousness of substance abuse to deter people, especially the youth, from alcohol and drug use.

\section{Limitations}

The study was carried out in a single region and district, and hence the findings may not be a true reflection of what pertains to the entire youth population. Therefore it is recommended that researchers who are interested in conducting a similar study should at least consider more than half of the regions in Ghana. 


\section{Conclusion}

The findings of the study confirmed that the gender and culture of a person could make one susceptible to substance use. Substance abuse is regarded as a risky activity. The findings also showed that there is a high awareness among the youth about different types of substances available and their general effects on the individual, family, and the nation. Therefore, such knowledge can be capitalized to serve as a protective factor against experimental substance use. Mass media campaigns can also be used to change norms regarding substance use. The study further revealed that poor parental supervision and peer influence are the main cause of substance use and abuse. It was also evident that HIV/AIDS, low productivity, insecurity, and humiliation remain the dominant effect of substance abuse. Moreover, the study showed that Rehabilitation remains the ultimate intervention for SUDs; however, limited rehabilitation facilities and stigma associated with SUDs interfere with treatment. The rate at which the youth is getting into substance use and abuse is becoming abhorring. It is, therefore, necessary for stakeholders such as Ghana Education Services, Ghana Health Services, Social Welfare Department, Parents, etc. to come together and set up home and school-based drug prevention units to educate the youth at a very tender age about substance abuse and its related disorders as well as the devastating consequences on the individual, family and the society as a whole.

Again, stakeholders interested in addressing substance abuse and its related disorders can also come together and use the media to reframe SUDs as a public health issue, enabling the government to allocate more funding towards substance use rehabilitation.

Finally, the study recommends that the Ministry of Health, Ghana Health Services, and other stakeholders should consider establishing rehabilitation support in communities to help substance abusers. The value of fines and prison sentences for civil penalties outlined in the Narcotics Commission Bill is not enough to deter people from drug use or reform prisoners who are convicted for drug use. It is, therefore, necessary for the government to set up affordable and effective residential rehabilitation facilities to offer focused-rehab programs or ongoing addiction support.

\section{List Of Abbreviations}

\section{Abbreviations Meaning}

DSM-V Diagnostic and Statistical Manual of Mental Disorders

SUDs Substance Use Disorders

KATH Komfo Anokye Teaching Hospital

\section{Declarations}

Acknowledgements 
We wish to thank the people of Kwabre for their involvement in this study

\section{Authors' contributions}

VK and EA conceptualized and prepared the study design and carried out the data collection exercise. FEO, MO, AG, and AUW did the analysis. All the authors took part in the preparation and of this manuscript.

\section{Funding}

There is no funding to report as this study received no funding support, and the authors funded the study through their individual contributions.

\section{Availability of data and materials}

The full data is available at the research repository of the Department of Health Promotion and Disability Studies, KNUST-Ghana.

\section{Ethics approval and consent to participate}

The participants were fully informed about the procedures and risks or benefits involved in the research. They gave their consent to participate in the study by signing a consent form. They had the opportunity to withdraw or cease their participation without any coercion. Anonymity was ensured as no identifying information was attached to their responses.

\section{Consent for publication}

Participants have consented to publication.

\section{Competing interest statement}

The authors do not have any competing interests as far as this submission is concerned.

\section{Data Availability}

The complete data can be accessed from the research repository of the department of health promotion and Disability Studies, KNUST.

\section{References}

1. Adzrago D. Doku DT. Adu-Gyamfi AB. Experiences of Individuals with Alcohol and Drug Addiction at Rehabilitation Centres in Ghana. J Addict Res Ther 2018:9: 363. doi:10.4172/2155-6105.1000363.

2. National Institute on Drug Abuse, Cigarettes and Other Tobacco Products. 2016:1-6. 
3. Feinstein EC. Richter L. Foster SE. Addressing the critical health problem of adolescent substance use through health care, research, and public policy. Journal of Adolescent Health, 2012:50(5), 431436. http://doi.org/10.1016/j.jadohealth.2011.12.033.

4. Mason MJ. Mennis J. Schmidt CD. A social operational model of urban adolescents' tobacco and substance use: A mediational analysis. Journal of Adolescence, 2011:34(5), 1055-1063. http://doi.org/10.1016/j.adolescence.2010.11.002

5. Amoakwa-Fordjour G. The breakdown of Ghana's mental healthcare.2013.

6. Appiah R, Boakye KE, Ndaa P, Aziato L. "Tougher than ever": An exploration of relapse prevention strategies among patients recovering from poly-substance use disorders in Ghana. Drugs: Education, Prevention and Policy. 2018 Nov 2; 25(6):467-74

7. American Psychiatric Association. Diagnostic and statistical manual of mental Disorders (5th ed., Text Revision). Washington, DC: American Psychiatric Association. 2013

8. American Society of Addiction Medicine. 'Opioid Addiction Disease': 2015 Facts \& Figures, 2015, 12. http://doi.org/10.2105/AJPH.2005.071647?journalCode=ajph.

9. World Health Organisation. Management of substance abuse. World Health Organisation. 2014:23(4), 1. http://doi.org/11/01/16.

10. United Nations Office on Drugs and Crime, World Drug Report (ISBN: 978-92-1-148291-1, elSBN: 97892-1-060623-3, United Nations publication, Sales No. E.17.XI.6) 2017

11. United Nations Office on Drugs and Crime: 35 million people worldwide suffer from drug use disorders and only 1 in 7 people receive treatment https://www.unodc.org/unodc/en/frontpage/2019/June/world-drug-report-2019_-35-million-peopleworldwide-suffer-from-drug-use-disorders-while-only-1-in-7-people-receive-treatment.html [Accessed on 29th July 2021]

12. Substance Abuse and Mental Health Services Administration, Centre for Behavioural Health Statistics and Quality. (July 17, 2014). The TEDS Report: Age of Substance Use Initiation United States Department of Justice. Among Treatment Admissions Aged 18 to 30. Rockville, MD

13. National Drug Intelligence Centre The Economic Impact of Illicit Drug Use on American Society. Washington D.C.: 2011

14. Canadian Centre on Substance Use and Addiction: Canadian Substance Use Costs and Harms 2015-2017

15. UNODC, World Drug Report 2012 (United Nations publication, Sales No. E.12.XI.1)

16. International Narcotics Control Board. Report of the International Narcotics Control Board for 2014.

17. Equal A. (Substance abuse is 3rd highest cause of psychiatric cases at KATH. 2015 https://www.myjoyonline.com/substance-abuse-is-3rd-highest-cause-of-psychiatric-cases-at-kath/ [Accessed on March 30, 2021].

18. Lucia B. Domestic Drug Consumption in Ghana: An under-reported phenomenon. [Online] Geneva, Global Initiative against Transnational Organized Crime. 2019. Available from: 
http://www.Globalinitiative.net $\mathrm{CH}-1211$ [Accessed on $10^{\text {th }}$ November 2020].

19. Acuda W. Caleb JO. Anne O. Ilana BC.'The Epidemiology of Addiction in Sub-Saharan Africa: A Synthesis of Reports, Reviews, and Original Articles'. Journal on Addictions [online] 2011:DOI: 10.1111/j.1521-'0391.2010.00111.x [Accessed on 17December, 2019].

20. Nyabor Jonas. (Tramadol abuse responsible for student rioting - GES reveals. 2018 https://citinewsroom.com/2018/06/tramadol-abuse-responsible-for-student-rioting-ges-reveals

21. Bryman A. The research question in social research: what is its role? International journal of social research methodology. 2007 Feb 1; 10(1):5-20.

22. Lipworth W, Taylor N, Braithwaite J. Can the theoretical domains framework account for the implementation of clinical quality interventions?. BMC health services research. 2013 Dec;13(1):1-3.

23. Mensah, EA. Substance Use among Students of a Second Cycle Institution in Accra. 2018

24. UNODC. World Drug Report finds drug use stable, access to drug \& HIV treatment still low, 0-2. (2015a).

25. NIDA. Is abuse of prescription medications as dangerous as other forms of illegal drug use? [Retrieved from https://www.drugabuse.gov/publications/principles-adolescent-substance-usedisorder-treatment-research-based-guide/frequently-asked-questions/abuse-prescriptionmedications-dangerous-other-forms-illegal-drug-use.2020 [Accessed on 2021, March 30]

26. King KM. Chassin L. A prospective study of the effects of age of initiation of alcohol and drug use on young adult substance dependence. Journal of Studies on Alcohol and Drugs, 2007:68(2), 256-265

27. Adu-Mireku S. The Prevalence of Alcohol, Cigarette, and Marijuana Use Among Ghanaian Senior Secondary Students in an Urban Setting.Journal of Ethnicity in Substance Abuse, 2003;2(1), 53-65. http://doi.org/10.1300/J233v02n01_05

28. Alberta Health Services; AADAC."The ABCs - Codeine and Other Opioid Painkillers". Alberta Alcohol and Drug Abuse Commission. 2007.

29. Barclay, R .4 Illegal Drugs That Might Be Medicines https://www.healthline.com/health-news/mentalfour-illegal-drugs-with-medicinal-qualities-2014:113013 [Accessed on 29th March 2021].

30. Clark DB. Thatcher DL. Maisto S. Supervisory neglect and adolescent alcohol use disorders: Effects on AUD onset and treatment outcome. Addict Behav. 2005:30:1737-1750.

31. Hilliard J. The Influence of Social Media on Teen Drug Use. 2019 https://www.addictioncenter.com/community/social-media-teen-drug-use [Accessed on March 30, 2021].

32. United Nations Office on Drugs and Crime (2016) World drug report 2016. New York: United Nations.

\section{Table}

Table 1 showing the Demographic characteristics of participants. 


\begin{tabular}{|c|c|c|c|}
\hline \multirow[t]{2}{*}{ DEMOGRAPHICS } & \multicolumn{2}{|l|}{ SEX } & \multirow[t]{2}{*}{ TOTAL } \\
\hline & Male & Female & \\
\hline \multicolumn{4}{|l|}{ Age Range } \\
\hline Below 20 years & 2 & - & 2 \\
\hline $20-24$ years & 12 & 7 & 19 \\
\hline $25-29$ years & 5 & 4 & 9 \\
\hline \multirow[t]{2}{*}{$30-35$ years } & 3 & 2 & 5 \\
\hline & & & 35 \\
\hline \multicolumn{4}{|l|}{ Educational level } \\
\hline Primary & 2 & - & 2 \\
\hline J.H.S. & 5 & 8 & 13 \\
\hline S.H.S. & 6 & 1 & 7 \\
\hline \multirow[t]{2}{*}{ Tertiary } & 9 & 4 & 13 \\
\hline & & & 35 \\
\hline \multicolumn{4}{|l|}{ Employment status } \\
\hline Employed & 7 & 7 & 14 \\
\hline \multirow[t]{2}{*}{ Unemployed } & 15 & 6 & 21 \\
\hline & & & 35 \\
\hline \multicolumn{4}{|l|}{ Religion } \\
\hline Islam & 3 & - & 3 \\
\hline \multirow[t]{2}{*}{ Christianity } & 15 & 17 & 32 \\
\hline & & & 35 \\
\hline \multicolumn{4}{|l|}{ Marital Status } \\
\hline Single & 16 & 10 & 26 \\
\hline \multirow[t]{2}{*}{ Married } & 6 & 3 & 9 \\
\hline & & & 35 \\
\hline
\end{tabular}

Source: fieldwork, 2020 